\title{
Experimental Characterization and Modeling of the Uniaxial Mechanical Behavior of Polypropylene before Necking
}

\author{
N. Brusselle-Dupend ${ }^{1 *}$, D. Lai ${ }^{1}$, X. Feaugas ${ }^{2}$, M. Guigon ${ }^{1}$ and M. Clavel ${ }^{1}$ \\ 1 Université de technologie de Compiègne, Laboratoire Roberval, BP 20529 - 60205 Compiègne Cedex - France \\ 2 Université de La Rochelle, Laboratoire d'études des matériaux en milieux agressifs, \\ Avenue Michel-Crépeau - 17042 La Rochelle Cedex 01 - France \\ e-mail: nadege.dupend@utc.fr - dawei.lai@utc.fr - xavier.feaugas@univ-lr.fr - michele.guigon@utc.fr - michel.clavel@utc.fr \\ * Author to whom correspondence should be addressed
}

\begin{abstract}
Résumé - Caractérisation expérimentale** et modélisation du comportement mécanique uniaxial du polypropylène avant striction - Des essais mécaniques ont été menés dans le domaine de la préstriction d'un polypropylène (PP) afin de caractériser son comportement mécanique. Ceux-ci ont permis de distinguer le comportement viscoélastique du comportement viscoplastique. Des outils développés depuis longtemps pour l'étude des métaux ont été employés afin d'examiner l'effet des hétérogénéités sur les différentes caractéristiques du comportement viscoplastique du polymère. Des développements particuliers ont été nécessaires pour adapter ces méthodologies au PP. La partition de la contrainte macroscopique initialement introduite par Cottrell a permis de distinguer la contrainte effective associée à la phase amorphe de la contrainte interne, de sorte que les interactions entre les lamelles cristallines et la phase amorphe soient prises en compte.

La modélisation du comportement viscoélastoplastique du PP est effectuée sur la base de la partition de la déformation totale en une déformation viscoélastique et une déformation viscoplastique. Le modèle rhéologique de Zener sert de point de départ à la description du comportement viscoélastique. La modélisation viscoplastique repose, quant à elle, sur la caractérisation du comportement en termes de contrainte effective et de contrainte interne associée à des incompatibilités de déformation.
\end{abstract}

** Un article consacré à la caractérisation expérimentale du comportement mécanique uniaxial du polypropylène a été publié en janvier 2001 dans la revue Polymer Engineering and Science [7].

Abstract - Experimental Characterization** and Modeling of the Uniaxial Mechanical Behavior of Polypropylene before Necking - Mechanical tests were performed in the pre-necking domain of polypropylene (PP) to characterize its mechanical behavior. Test results have distinctly characterized both its viscoelastic and its viscoplastic behavior. The usual approach to studying metals was adopted to investigate the effect of heterogeneities on the different features of the viscoplastic behavior of the polymer. Particular developments were necessary to adapt these methods to the semicrystalline polypropylene. By the macroscopic approach initially introduced by Cottrell, the macroscopic stress was split into an effective stress and a back stress so that the interactions between the crystalline lamellae and the amorphous phase could be taken into account. 
The modeling of the viscoelastoplastic behavior of PP is described by using the partition of total strain into a viscoelastic strain and a viscoplastic strain. The rheological model of Zener was used and improved with the experimental observations to model the viscoelastic behavior. As for viscoplastic behavior modeling, it's based on the characterization of the mechanical behavior in terms of effective stress and back stress associated with incompatibilities of deformation.

\footnotetext{
** A paper entirely devoted to the experimental characterization of the uniaxial mechanical behavior of polypropylene was published in January 2001 in Polymer Engineering and Science [7].
}

\section{INTRODUCTION}

Polymers are an integral part of our daily life. In a relatively recent economic analysis [1], a new classification of polymer products according to their life span is proposed. They can be classified into three parts:

- disposable products intended to disappear before one year;

- durable goods intended to last, used between one and twenty years;

- infrastructures whose life span is superior to twenty years.

This analysis forecasts an increasing world production of polymers in the future years as well in industrial countries as in developing countries. In particular, the semicrystalline polypropylene (PP), which is mainly used at present for conveniences, would head the list of polymers employed for semitechnique applications in twenty years. The performance, the cheap cost and the lightness of this thermoplastic would be the assets of its promising future. It is therefore important to develop constitutive equations able to describe the behavior of this kind of semicrystalline polymer (SCP) under different loading paths in order to improve the structural design.

The mechanical properties of SCPs strongly depend on their processing techniques and on the resulting microstructural morphology. Although numerous studies deal with the mechanical behavior of these biphased materials, their mechanisms of deformation are not well-understood and several points are still obscure; in particular, the role of the interface between the crystalline and the amorphous phases during the deformation, the interactions between the two phases, the role of the crystalline phase during the plastic deformation, etc. Moreover, heavy and devoid of physical meaning expressions are often necessary to take the viscosity inherent in these materials into account in models.

In this paper, the uniaxial mechanical behavior of PP is first analysed with suitable mechanical tests. Tools specific to metals are employed to characterize the heterogeneities of the biphased material. Based on these considerations, a model is then proposed to describe the mechanical behavior of PP under a few loading paths [2].

The studied domain in terms of deformation concerns the small strain domain, and especially the pre-necking domain.

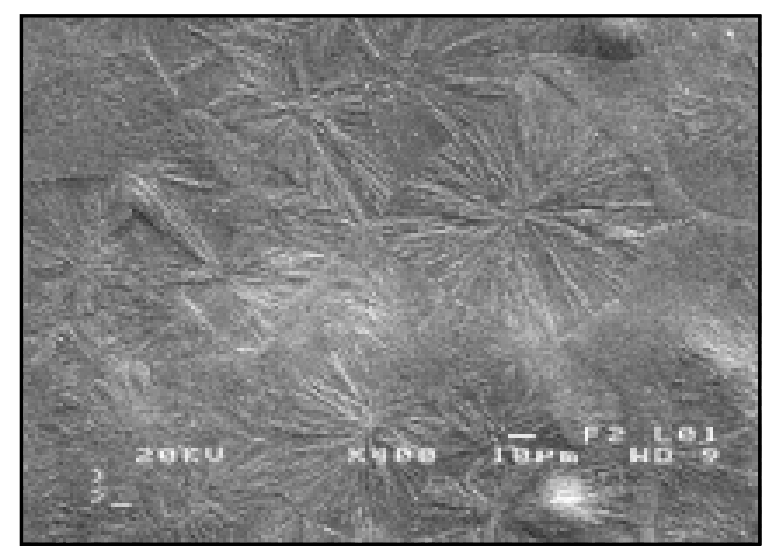

(a)

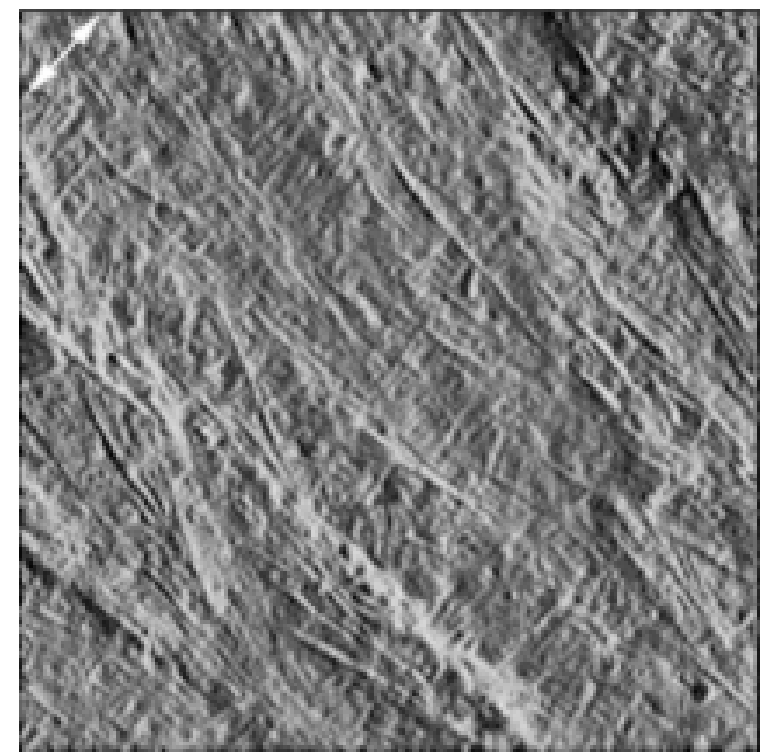

(b)

Figure 1

Microstructural observations of the studied polypropylene. (a): scanning electron micrograph showing general view of the spherulitic morphology in the midthickness of an undeformed PP plate, view perpendicular to extrusion direction

(b): a SFM image $(3 \times 3 \mu \mathrm{m}$, nanoscope III in tapping mode $)$ obtained on the midthickness of an undeformed PP sample: observation of the crystalline structure, $\leftrightarrow$ : extrusion direction, z-range (amplitude-range) $=0.15 \mathrm{~V}$. 
Numerous papers deal with the mechanical behavior of highly strained SCPs whereas polymers are in most cases subjected to small strains.

\section{POLYPROPYLENE: A SEMICRYSTALLINE POLYMER}

Plates of polypropylene were manufactured and processed by extrusion by the MPS firm (ISOSUD): their thickness is equal to $4 \mathrm{~mm}$ [2]. This thermoplastic presents a spherulitic morphology where live together a crystalline phase and an amorphous phase (Fig. 1a). Microstructural observations have shown that the studied PP presents a homogeneous spherulites size only in $60 \%$ of plate thickness: the average spherulite size is $35 \mu \mathrm{m}$ in the core. However, no significant distorsion of their shape possibly caused by the processing techniques was noticed.

The degree of crystallinity of PP was evaluated at $40 \%$ with a differential scanning calorimetry (DSC) using a Setaram instrument operating a heating rate of $5^{\circ} \mathrm{C} \mathrm{min}{ }^{-1}$. PP's glass transition temperature $\left(T_{g}\right)$ was determined at $281.7 \mathrm{~K}$ by dynamic mechanical analysis (DMA) using a Perkin Elmer instrument: the amorphous phase is therefore in a rubber-like state at room temperature.

The analysis of diffraction peaks obtained by X-ray diffraction patterns of the core sample has revealed that the crystalline fraction of PP is composed entirely of the monoclinic $\alpha$-form. Photo on Figure 1b achieved with scanning force microscopy (SFM) on initially etched [3] PP sample reveals the complex lamellar structure of the crystalline phase: Figure $1 \mathrm{~b}$ mainly shows the radial lamellae which appear as bundles of lamellae, and "daughter" lamellae joined up to radial lamellae seem to be detected.

Moreover, the examination of the crystalline texture with a X-ray diffraction goniometer shows a very slight initial anisotropy caused by the orientation of (040) planes [2].

The morphology of the studied semicrystalline polypropylene is consequently relatively homogeneous in spite of its industrial origin.

\section{VISCOELASTOPLASTIC BEHAVIOR OF POLYPROPYLENE BEFORE NECKING}

Viscoelastic behavior has only been admitted in the pre-necking domain of SCPs for a long time. Occasionally, plasticity has just been suspected to explain the difficulty of viscoelastic models to predict the behavior of polymers in the small strains domain [4-6].

In this study, convincing mechanical tests were therefore performed to characterize properly the behavior of PP before necking [7]. Tensile loading tests determined that necking occurs at about $11 \times 10^{-2}$ strain level.

\subsection{Evidence of the Viscoelastoplastic Behavior of Polypropylene}

Iso-type specimens were manufactured in extruded plates of $\mathrm{PP}$, the longitudinal axis corresponding to the direction of extrusion (" 0 " direction). The tests were performed at room temperature with an electromechanical tensile machine INSTRON 4505. The strain rate $\dot{\varepsilon}$ used is equal to $8 \times 10^{-5}$ $\mathrm{s}^{-1}$ : this relatively slow strain rate was chosen because viscosity expresses more itself for any slow $\dot{\varepsilon}$.

The characterization of the behavior of PP was simply achieved from loading-unloading-recovery mechanical tests. This kind of tests consisted in loading the material with a constant strain rate up to a strain level $\varepsilon_{t}$. Then, at $\varepsilon_{t}$ (whose corresponding stress is $\sigma_{\max }$ ), reversal loading is applied up to zero stress. As soon as the stress reaches zero, the evolution of the strain with time is followed.

Three types of behavior were observed in the pre-necking domain of PP. Hysteresis phenomenon appears at very low strain levels (Fig. 2a). As $\varepsilon_{t}$ rises, strain level plotted at the end of instantaneous unloading, $\varepsilon_{\text {res }}$, is different from zero, but is completely recovered in time (Fig. 2b). For higher $\varepsilon_{t}$, $\varepsilon_{\text {res }}$ is only partially recovered in time (Fig. $2 c$ ): the stabilized strain level determined with a strain rate offset of $10^{-8} \mathrm{~s}^{-1}$ is called permanent strain $\left(\varepsilon_{\text {perm }}\right)$.

The complete recovery in time of $\varepsilon_{\text {res }}$ for low $\varepsilon_{t}$ implies that the material first presents a viscoelastic behavior. The detection of $\varepsilon_{\text {perm }}$ shows that the material presents a viscoplastic behavior. The studied polypropylene therefore presents a viscoelastic behavior (Stage I) preceding a viscoplastic behavior (Stage II). The transitional strain between both stages was accurately evaluated at $\varepsilon_{t}=1.5 \pm 0.3 \times 10^{-2}$ from several loading-unloading-recovery tests and noted $\varepsilon_{\mathrm{I} / \mathrm{II}}$; the corresponding stress value, for the strain rate studied, is $16 \pm 2 \mathrm{MPa}\left(\Sigma_{0}\right)$. In the following sections, plastic strain expression is employed to designate permanent strain.

\subsection{Effect of Processing Techniques on the Dimension of the Viscoelastic Stage}

The effects of processing techniques on the dimension of the viscoelastic domain were studied because of the industrial origin of the polymer [7]. Loading-unloading-recovery tests were then performed on specimens whose angle between their longitudinal axis and the extrusion direction was equal to $45^{\circ}$ (" $45^{\circ}$ " direction ) and $90^{\circ}$ ("90" $90^{\circ}$ direction). As illustrated in Figure 3a, there is no significant effect of the tensile axis direction on the macroscopic stress $v s$ strain results.

The close examination of the different tests led to the determination of the limit of viscoelasticity in terms of stress $\left(\Sigma_{0}\right)$ and strain $\left(\varepsilon_{\mathrm{I} / \mathrm{II}}\right)$ in the " 0 ", " $45^{\circ}$ " and " $90^{\circ}$ " directions. Figure $3 \mathrm{~b}$ shows that the deviation of the tensile axis from the extrusion direction results in an important increase of the viscoelastic strain domain. The slight initial anisotropy of the 


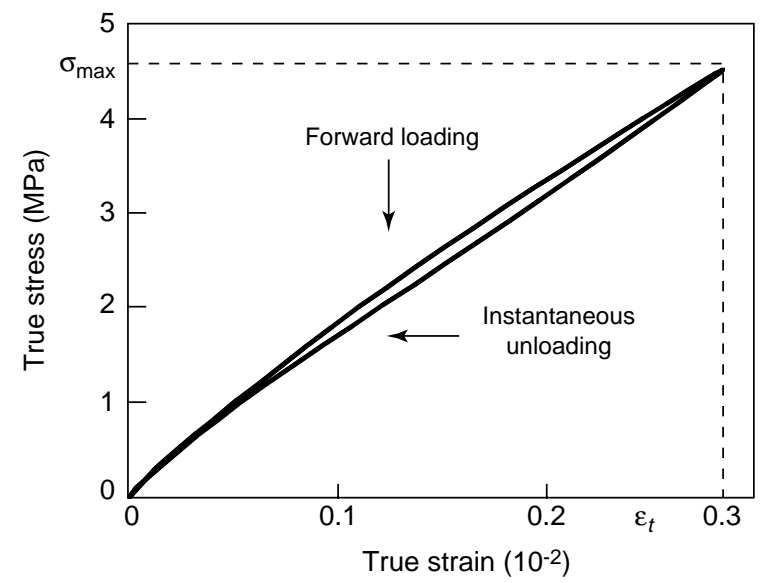

(a)
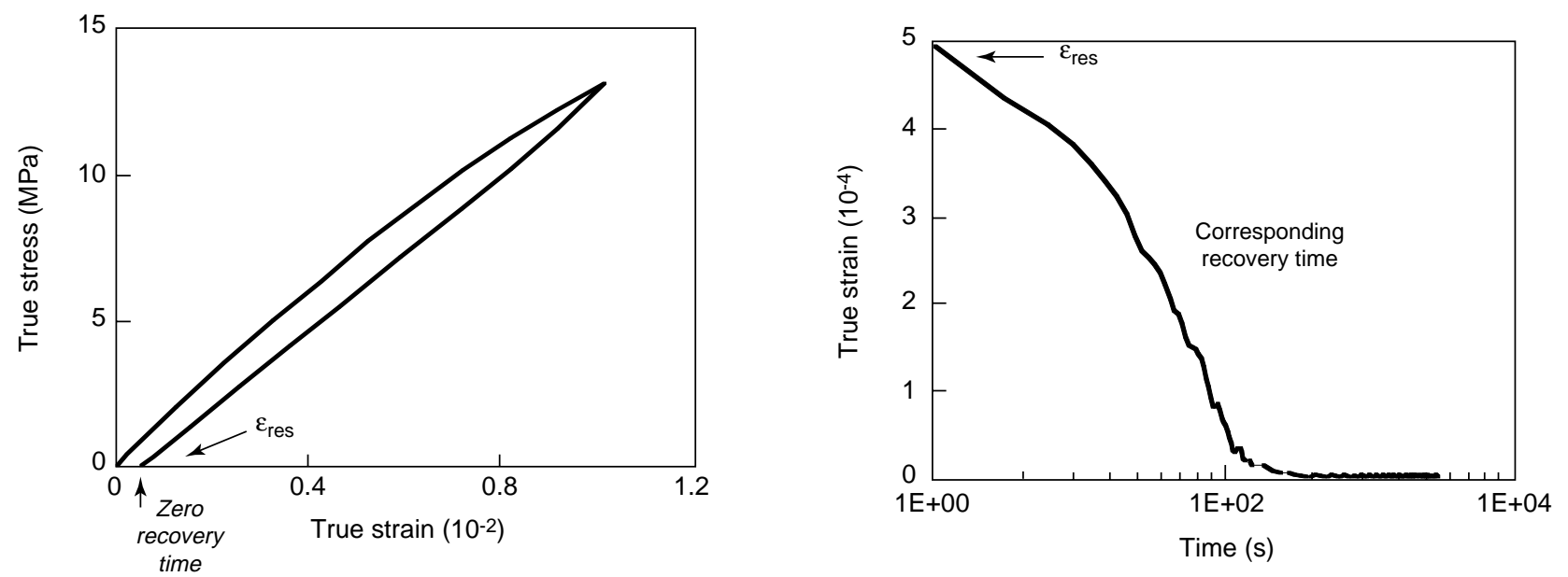

(b)
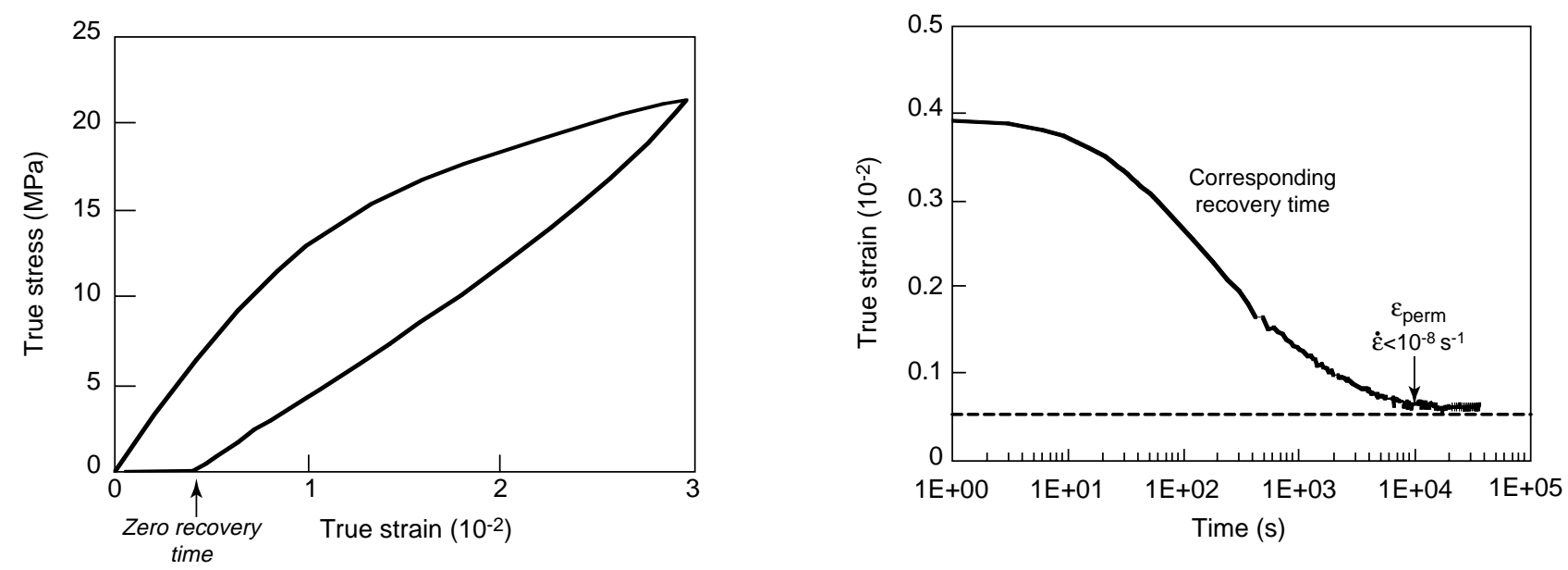

(c)

Figure 2

Experimental results of loading-unloading tests conducted up to different strain levels $\varepsilon_{t}$, with constant strain rate equal to $8 \times 10^{-5} \mathrm{~s}^{-1}$. On (b) and (c): presentation of their corresponding recovery time [7]. 


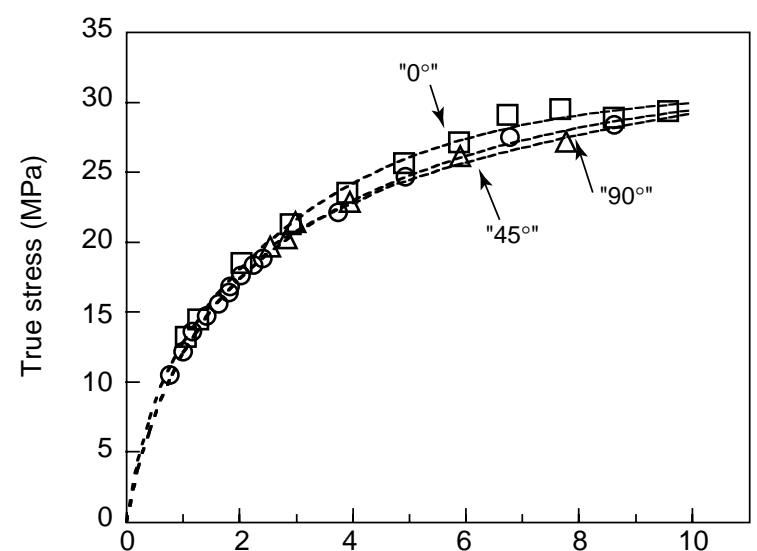

(a)

$$
\varepsilon_{t}\left(10^{-2}\right)
$$

$\left(\sigma_{\max }, \varepsilon_{t}\right)$ values obtained from "0॰ direction" iso-type

$\triangle\left(\sigma_{\max }, \varepsilon_{t}\right)$ values obtained from " $45^{\circ}$ direction" iso-type

○ $\left(\sigma_{\max }, \varepsilon_{t}\right)$ values obtained from " $90^{\circ}$ direction" iso-type

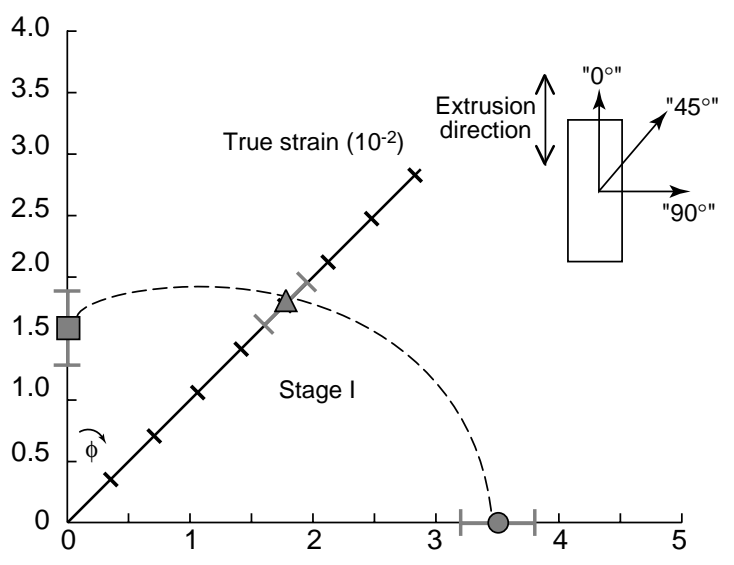

(b) $\square$ "0 direction"
$\triangle$ "45 direction"
$\quad$ "90 direction"

Figure 3

Influence of the tensile axis direction. (a): $\left(\sigma_{\max }, \varepsilon_{t}\right)$ values obtained from tensile tests performed on iso-type specimens in " $0^{\circ}$ ", " $45^{\circ}$ " and " $90^{\circ}$ " directions. (b): limit of viscoelasticity in terms of deformations $\varepsilon_{\mathrm{I} / \mathrm{II}}$ in the " $0^{\circ}$ ", " $45^{\circ}$ " and " $90^{\circ}$ " tensile axis. Polar coordinates representation.

material may be at the origin of this result. For the following tests, precautions were therefore taken to manufacture specimens in the same " 0 " " direction.

As a remark, the effect of macroscopic strain rate was also studied [7]: it was shown that $\Sigma_{0}$ and $\varepsilon_{\mathrm{I} / \mathrm{II}}$ do not appear to be very sensitive to the macroscopic strain rate in the range studied.

\section{EFFECT OF TIME ON THE MACROSCOPIC STRESS OF THE BIPHASED MATERIAL}

The tensile behavior of polypropylene was also analysed in terms of thermal (or viscous) and athermal (or elastoplastic) stresses through relaxation tests (loading and unloading strain rate is $8 \times 10^{-5} \mathrm{~s}^{-1}$ ).

\subsection{Stress Analysis Resulting from Relaxation Tests}

For this sort of test, the strain level $\varepsilon_{t}$ reached at the end of forward loading is held for $24 \mathrm{~h}$ so that the macroscopic stress presents a steady state $\left(\dot{\sigma}<3.6 \times 10^{-3} \mathrm{MPa} \mathrm{h}^{-1}\right)$. Reversal loading is applied after this relaxation phase.

Figure 4 shows the first decrease of stress with time during the relaxation test then its stabilization. For a given $\varepsilon_{t}$, the stabilized stress level is called $\sigma_{2}$ and the difference between $\sigma_{\max }$ and $\sigma_{2}$ corresponds to the stress that is affected by viscosity $\left(\sigma_{v}\right)$. Macroscopic stress is therefore divided into

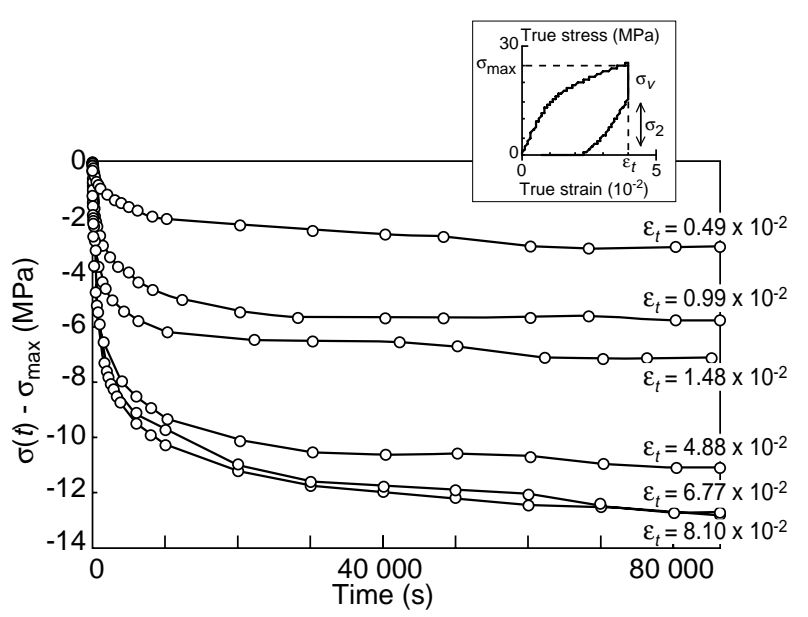

Figure 4

Experimental results of stress relaxation tests. Tests were conducted with loading up to $\varepsilon_{t}$ with a strain rate equal to $8 \times 10^{-5} \mathrm{~s}^{-1}$ [7].

thermal stress $\sigma_{v}$ and athermal stress $\sigma_{2}$. The two components first rise quickly against $\varepsilon_{t}$ (Fig. 5), but with a higher slope for $\sigma_{2}$. Then, from a strain level which corresponds to $\varepsilon_{\mathrm{I} / \mathrm{II}}, \sigma_{v}$ stabilizes at $12.5 \mathrm{MPa}$ until necking occurs, whereas $\sigma_{2}$ tends towards $16 \mathrm{MPa}$. 


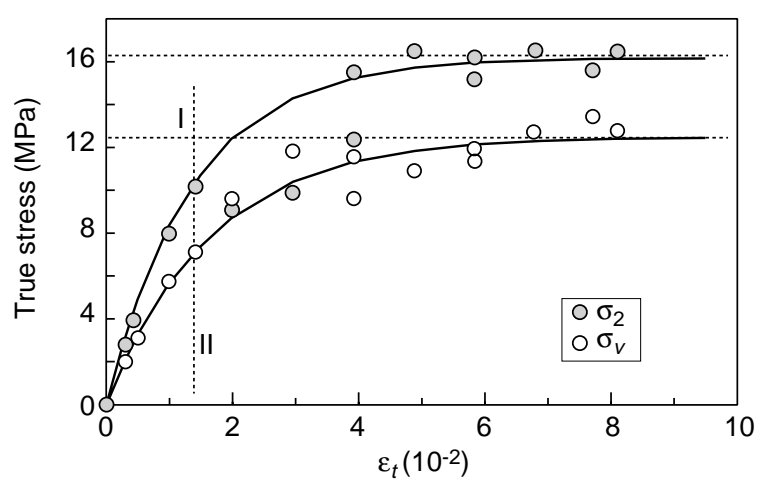

Figure 5

Athermal stress, $\sigma_{2}$, and thermal stress, $\sigma_{v}$, vs $\varepsilon_{t}$. Values resulting from relaxation tests [7].

\subsection{Evolutions of $\sigma_{2} v s \varepsilon_{t}$ and $\sigma_{y} v s \varepsilon_{t}$ at the Root of the Viscoelastic Modeling of Polypropylene}

The partition in Stage I of the multiphased polymer's macroscopic stress into an athermal stress, $\sigma_{2}$, and a viscous stress, $\sigma_{v}$, gives the basis of a viscoelastic model. The relaxation of macroscopic stress can be associated with the relaxation of the stress in the amorphous phase of the polymer whose macromolecules are "free" to move at room temperature. After the stabilization of the relaxed stress, the stress level corresponds to the athermal stress associated with the crystalline phase of PP.

This experimental characterization therefore leads to model the viscoelastic behavior of PP from a rheological model where the stress in the crystalline phase $\left(\sigma_{2}\right)$ is parallel to the stress in the amorphous phase $\left(\sigma_{v}\right)$. The elastic behavior of the hard phase and the viscous behavior of the soft phase therefore involve to use the classical rheological model of Zener [8] as a starting point (see Section 5).

\subsection{Mechanical Behavior of PP in Stage II}

When permanent strain is detected (in Stage II), the relation between the mechanical response of the SCP and its microstructural morphology is more complex. In this work, a method initially introduced for the study of metals at $T<0.5 T_{m}$ ( $T_{m}$ corresponds to the melting temperature) is used in an attempt to analyse in details the interactions between the different phases at the origin of the viscoplastic behavior of PP.

\section{CHARACTERIZATION OF THE VISCOPLASTIC BEHAVIOR OF THE MULTIPHASED MATERIAL}

The notions of effective stress $\left(\sigma_{\text {eff }}\right)$ and back stress associated with long-range interactions $(X)$ are usually used in metals to improve the understanding of their plastic strain mechanisms [9-12].

\subsection{Stresses Analysis from a Method Initially Introduced for the Study of Metals at $T<0.5 T_{m}$}

In metals at $T<0.5 T_{m}$, it has been shown that the macroscopic stress $\left(\sigma_{\max }\right)$ can be divided into a macroscopic effective stress $\left(\sigma_{\text {eff }}\right)$ associated with short-range interactions and macroscopic back stress $(X)$ associated with long-range interactions at the origin of the plastic strain [13-15]. In previous works, the internal stress has been used to refer to the stress associated with long-range interactions.

The macroscopic effective stress is the mechanical stress locally necessary (short-range) to permit dislocations to clear the barrier of energy associated with located obstacles then to move. As for the back stress, this macroscopic component results from long-range interactions emerging from physical phenomena. The local and no polarized nature of $\sigma_{\text {eff }}$ gives this component an isotropic character (isotropic hardening defined by a scalar); whereas $X$ has a tensorial definition because of its polarized nature (kinetic hardening defined by a tensor). In the stress space, $X$ therefore corresponds to the translation of an elastic domain which $\sigma_{\text {eff }}$ represents the radius of

The determination of $X$ and $\sigma_{\text {eff }}$ corresponding to a plastic strain level can be achieved with the method of Cottrell [10]. To determine the location and the size of the elastic domain, this method requires the plastic straining direction reversal: the reverse yield stress $\left(\sigma_{r}\right)$ is smaller than the yield stress $\left(\sigma_{Y}\right)$ measured during the forward loading (Bauschinger effect). At the beginning of the plasticity reversal, the back stress assists the applicated stress which has already been reversed. At the maximum macroscopic stress $\sigma_{\text {max }}$, back stress associated with long-range interaction opposes to the applicated stress. The stress level at the end of forward loading can therefore be expressed as the sum of back stress and effective stress in the following way:

$$
\sigma_{\text {eff }}=\frac{1}{2}\left(\sigma_{\max }-\sigma_{r}\right) \text { and } X=\sigma_{\max }-\sigma_{\text {eff }}
$$

The accurate determination of the linear elastic domain from the apparent elasticity modulus allows therefore the measure of $\sigma_{\text {eff }}$ and $X$.

\subsection{Stresses Analysis of Polypropylene in Terms of Effective and Back Stresses}

The previous stress partition, proposed by Cottrell [10], provides a method to measure effective stress and back stress associated with plastic strain heterogeneities caused by the studied material's multiphased structure. 
When the material first presents linear elastic behavior, it is easy to obtain a reverse yield stress value with the help of a plastic strain offset. However, PP initially behaves in a no linear elastic way (Fig. 2). In the present work Cottrell's method was modified to establish the evolution of the SCP's viscoelastic domain from the hysteresis loop of loadingunloading tests. For a loading (up to $\varepsilon_{t}$ )-unloading test, the diameter $\alpha$ of the viscoelastic domain is obtained from the superimposition of the corresponding unloading curve on the viscoelastic unloading curve provided by a loadingunloading test performed up to $\varepsilon_{t}=\varepsilon_{\mathrm{I} / \mathrm{II}}$ [7]. With this method, the apparent effective stress $\sigma_{\text {eff }}$ and the apparent back stress $X$ are defined as follows:

$$
\sigma_{\text {eff }}=\frac{\alpha}{2} \text { and } X=\sigma_{\max }-\frac{\alpha}{2}
$$

This modified Cottrell's method was then applied to a set of loading-unloading-recovery tests performed at $\dot{\varepsilon}=$ $8 \times 10^{-5} \mathrm{~s}^{-1}$ and $\dot{\varepsilon}=1.6 \times 10^{-3} \mathrm{~s}^{-1}$. The corresponding $\sigma_{\text {eff }} v s$ $\varepsilon_{t}$ and $X v s \varepsilon_{t}$ evolutions are reported on Figure 6 .

$\sigma_{\text {eff }}$ falls at the beginning of the viscoplastic domain, whereas $X$ increases markedly. From $\varepsilon_{t} \approx 6 \times 10^{-2}, \sigma_{\text {eff }}$ stabilizes at a few $\mathrm{MPa}$, whereas $X$ tends towards $27 \mathrm{MPa}$ for $\dot{\varepsilon}=8 \times 10^{-5} \mathrm{~s}^{-1}$ and towards $32 \mathrm{MPa}$ for $\dot{\varepsilon}=1.6 \times 10^{-3} \mathrm{~s}^{-1}$. The softening of $\sigma_{\text {eff }}$ would result from an easier viscoplastic flow in the amorphous phase of PP, while the hardening of $X$ could be attributed to an increase in plastic strain incompatibilities caused by the behavior of the different phases (amorphous and crystalline) present in the material.
An important effect of strain rate can be noticed on the $\sigma_{\text {eff }}$ $v s \varepsilon_{t}$ and $X v s \varepsilon_{t}$ evolutions: the higher $\dot{\varepsilon}$ is, the more quickly $X$ increases and $\sigma_{\text {eff }}$ falls. These last results highlight the necessity to attribute a thermal component and an athermal component to $\sigma_{\text {eff }}$ and to $X$. The thermal component of macroscopic stress depends on strain rate which is not the case of the athermal component. In metal alloys at $T<0.5 T_{m}$, such a distinction between thermal and athermal stress has already been made by Dickson and coworkers [12] who discussed Cottrell's method in detail.

For PP, note that relaxation tests permit the evaluation of the sum of the thermal components of $\sigma_{\text {eff }}$ and $X$ from the viscous stress relaxed during this kind of tests. Moreover, the sum of the athermal components of $\sigma_{\text {eff }}$ and $X$ can be determined from the stabilized stress level $\sigma_{2}$ at the end of relaxation. A good estimation of $\sigma_{\mathrm{eff}}^{\text {ath }}$ and $X^{\text {ath }}$ can therefore be obtained from the relaxation tests.

The evolutions of the athermal components of apparent effective stress $\left(\sigma_{\text {eff }}^{\text {ath }}\right)$ and the athermal components of back stress $\left(X^{\text {ath }}\right)$ against $\varepsilon_{t}$ were obtained from the application of the modified Cottrell's method to a set of loading-relaxationunloading tests (Fig. 6).

As shown in Figure 6, no values of athermal components of effective and back stresses are reported for small strain values: $\sigma_{\text {eff }}^{\text {ath }}$ and $X^{\text {ath }}$ can only be measured for low $\sigma_{\text {eff }}^{\text {ath }}(i . e$. for high $\varepsilon_{t}$ ) because there is no compression after unloading. Consequently, for the beginning of the viscoplastic domain, $\sigma_{\text {eff }}^{\text {ath }}$ evolution was approximated as the evolution of $\sigma_{\text {eff }}$ from the loading-unloading tests performed at $\dot{\varepsilon}=1.6 \times 10^{-3} \mathrm{~s}^{-1}[7]$.

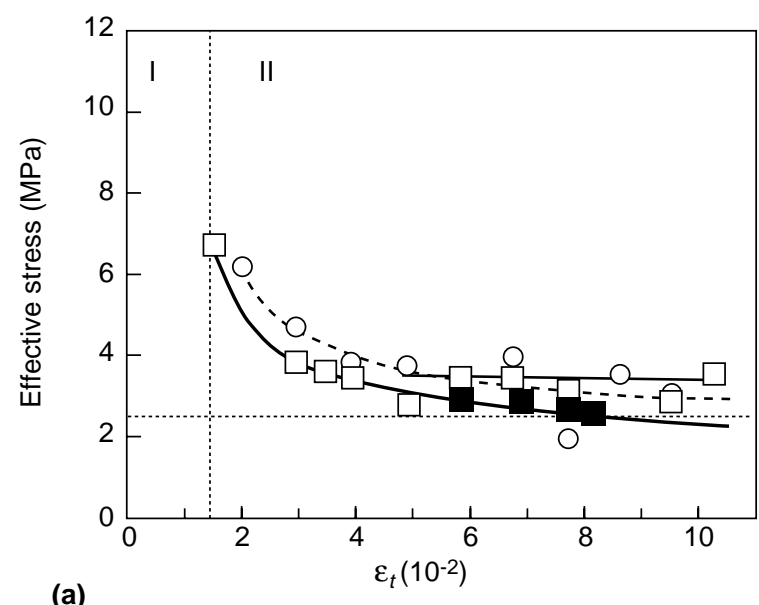

\begin{tabular}{c|c}
$\sigma_{\text {eff }}$ & $\sigma_{\text {eff }}^{\text {ath }}$ \\
\hline- - - from loading-unloading tests: $\dot{\varepsilon}=8 \times 10^{-5} \mathrm{~s}^{-1}$ & - \\
$-\square-$. from loading-unloading tests: $\dot{\varepsilon}=1.6 \times 10^{-3} \mathrm{~s}^{-1}$ & \\
$\square \quad$ from relaxation tests &
\end{tabular}

Figure 6

(a): effective stress $v s \varepsilon_{t}$. (b): back stress $v s \varepsilon_{t}[7]$.

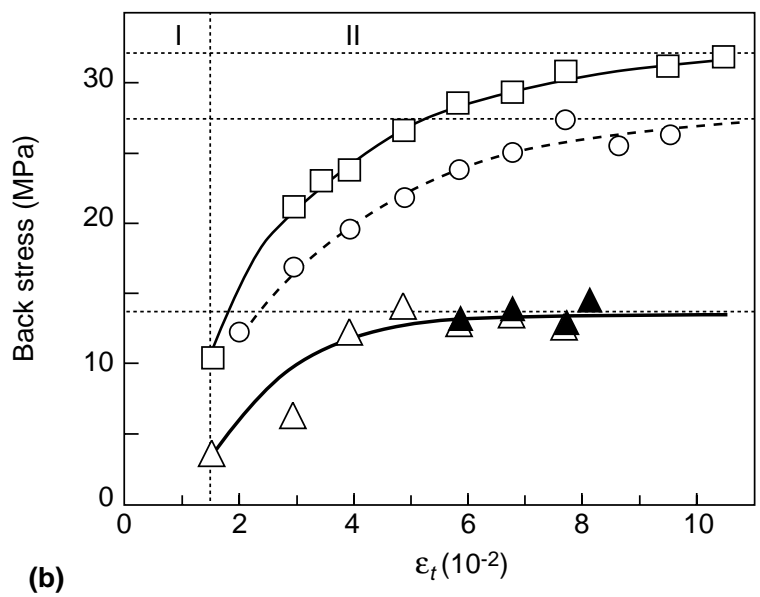

\begin{tabular}{c|c}
$X$ & $X$ ath \\
\hline$--\bigcirc-$ from loading-unloading tests: $\dot{\varepsilon}=8 \times 10^{-5} \mathrm{~s}^{-1}$ & \\
$-\square-\cdot$ from loading-unloading tests: $\dot{\varepsilon}=1.6 \times 10^{-3} \mathrm{~s}^{-1}$ & \\
$\triangle \quad$ from relaxation tests & \\
$\triangle \quad$ from $\sigma_{2}-\sigma_{\text {eff }}^{\text {ath }}$ &
\end{tabular} 
As illustrated in Figure 6, the athermal component of $\sigma_{\text {eff }}$ decreases markedly and stabilizes at about $2 \mathrm{MPa}$. From the evolution of $\sigma_{\text {eff }}^{\text {ath }} v s \varepsilon_{t}, X^{\text {ath }} v s \varepsilon_{t}$ is obtained as follows:

$$
X^{\text {ath }}=\sigma_{2}-\sigma_{\text {eff }}^{\text {ath }}
$$

The athermal component of $X$ increases from the beginning of Stage II then tends to saturate at about $14 \mathrm{MPa}$.

This analysis of the stresses evidences that macroscopic stress mainly originates in incompatibilities of deformation caused by the multiphased morphology. In addition, back stress is much more strongly affected by viscosity than effective stress.

\subsection{Evolutions of Back Stress and Effective Stress vs $\varepsilon_{v p}$ at the Root of the Viscoplastic Modeling of Polypropylene}

Out of the viscoelastic domain, the SCP presents permanent strain during the recovery time. Total strain can therefore be expressed as the sum of a viscoelastic strain $\left(\varepsilon_{v l}\right)$ and a viscoplastic strain $\left(\varepsilon_{v p}\right)$ :

$$
\varepsilon=\varepsilon_{v l}+\varepsilon_{v p}
$$

On the assumption that this strain partition is correct, the different components of macroscopic stress in Stage II particularly depend on their corresponding viscoplastic strain.

For $\varepsilon_{t}$ higher than the limit of viscoelasticity $\varepsilon_{\mathrm{I} / \mathrm{II}}$, the experimental measure of the corresponding $\varepsilon_{v p}$ value can only be performed at the end of relaxation tests when the relaxed stress level is stabilized (see Section 6.1).
It is unfortunately not possible to determine experimentally the $\varepsilon_{v p}$ value corresponding to $\varepsilon_{t}$ reached at the end of forward loading tests. In this case, the evaluation of $\varepsilon_{v p}$ corresponding to a given strain level can only be achieved from the response of a viscoelastic model; hence the importance of the development of a model able to predict the mechanical response of PP in Stage I.

\section{MODELING OF THE MECHANICAL BEHAVIOR OF THE SEMICRYSTALLINE POLYPROPYLENE IN STAGE I}

As shown in Section 3.2, the classical rheological model of Zener (Fig. 7a) can be used to model the viscoelastic behavior of a biphased material whose structure is divided into a hard phase (whose corresponding stress is $\sigma_{2}$ ) and a soft phase (whose corresponding stress is $\sigma_{v}$ ):

$$
\begin{gathered}
\sigma_{2}=C_{2} \varepsilon_{v l} \\
\frac{\mathrm{d} \sigma_{v}}{\mathrm{~d} t}=C_{1}\left(\frac{\mathrm{d} \varepsilon_{v l}}{\mathrm{~d} t}-\frac{\sigma_{v}}{\eta}\right)
\end{gathered}
$$

The stiffness of the spring which represents the crystalline phase behavior of PP is directly deduced from the linear $\sigma_{2}$ $v s \varepsilon_{t}$ evolution provided by the relaxation tests. As for the amorphous phase of PP, its viscous nature has led to model its behavior from a spring in series with a dashpot (Maxwell's model).

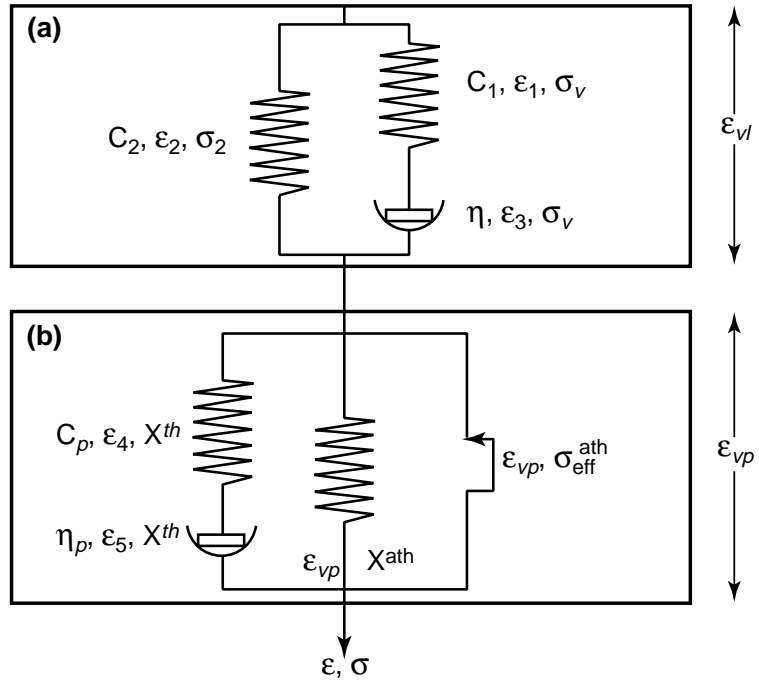

Figure 7

Modeling of the viscoelastoplastic behavior of polypropylene. (a): viscoelastic unit: Zener's rheological model. (b): viscoplastic unit.

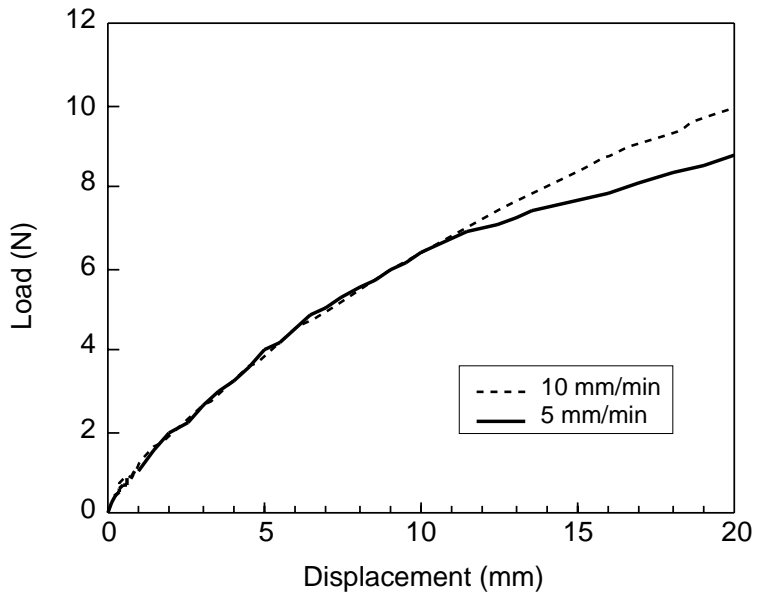

Figure 8

Tensile tests performed on PMMA at $T=130^{\circ} \mathrm{C}\left(T>T_{g}\right)$. 


\subsection{Description of the Amorphous Phase Viscous Behavior from Maxwell's Model: an Assumption}

To check that the amorphous phase behavior of PP can be modeled from Maxwell's model, mechanical tests were performed on a $100 \%$ amorphous polymer at $T>T_{g}$. Tensile tests were conducted on iso-type specimens of PMMA (polymethyl methacrylate) at $130^{\circ} \mathrm{C}$ in a crosspiece shifting rate range contained between 5 and $10 \mathrm{~mm} / \mathrm{min}$. Figure 8 shows that the initial slope of the load $v s$ displacement curves are not affected by the strain rate. This would tend to prove that the rubber-like amorphous phase behavior can be modeled from a Maxwell's model whose spring stiffness $C_{1}$ does not depend on $\dot{\varepsilon}$. Only the dashpot viscosity coefficient depends on $\dot{\varepsilon}$.

Concerning the viscoelastic modeling of PP, the value of $C_{1}$ can therefore be obtained from the initial slope $\left(C_{1}+\mathrm{C}_{2}\right)$ of the experimental tensile tests curves $\left(\sigma_{\text {exp }}, \varepsilon_{\text {exp }}\right)$.

\subsection{Material Viscosity Coefficient $\eta$ of Polypropylene}

The evolution of this parameter was achieved from the experimental stress-strain results of forward loadings at different strain rates: the $\eta, \dot{\varepsilon}_{1}$ and $\dot{\varepsilon}_{3}$ experimental values were determined from $\left(\sigma_{\text {exp }}, \varepsilon_{\text {exp }}, \dot{\varepsilon}\right)$ experimental data and the values of $C_{1}, C_{2}$. Figure 9 shows that the material's viscosity coefficient $\eta$ does not only decrease against the dashpot strain rate $\dot{\varepsilon}_{3}$ but depends on the total strain rate $\dot{\varepsilon}$ too. These experimental $\eta v s \dot{\varepsilon}_{3}$ evolutions reveal the non-Newtonian viscosity of PP.

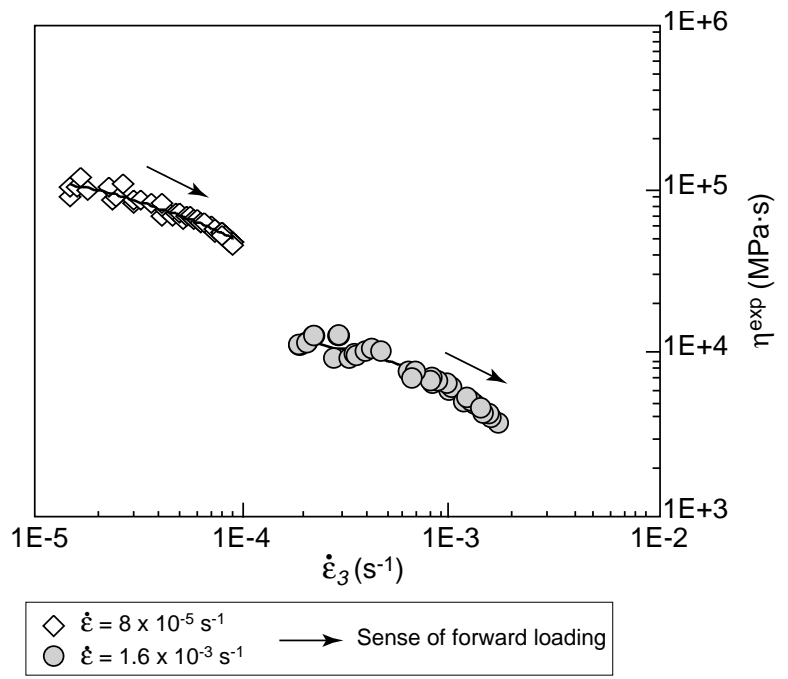

Figure 9

PP's viscosity $\eta v s$ dashpot strain rate $\dot{\varepsilon}_{3}$. Evolutions determined from the experimental data $\left(\sigma_{\text {exp }}, \varepsilon_{\text {exp }}\right)$ of two forward loading tests conducted up to $\varepsilon_{t}=1.3 \times 10^{-2}$ at $\dot{\varepsilon}=8 \times 10^{-5} \mathrm{~s}^{-1}$ and $\dot{\varepsilon}=1.6 \times 10^{-3} \mathrm{~s}^{-1}$.
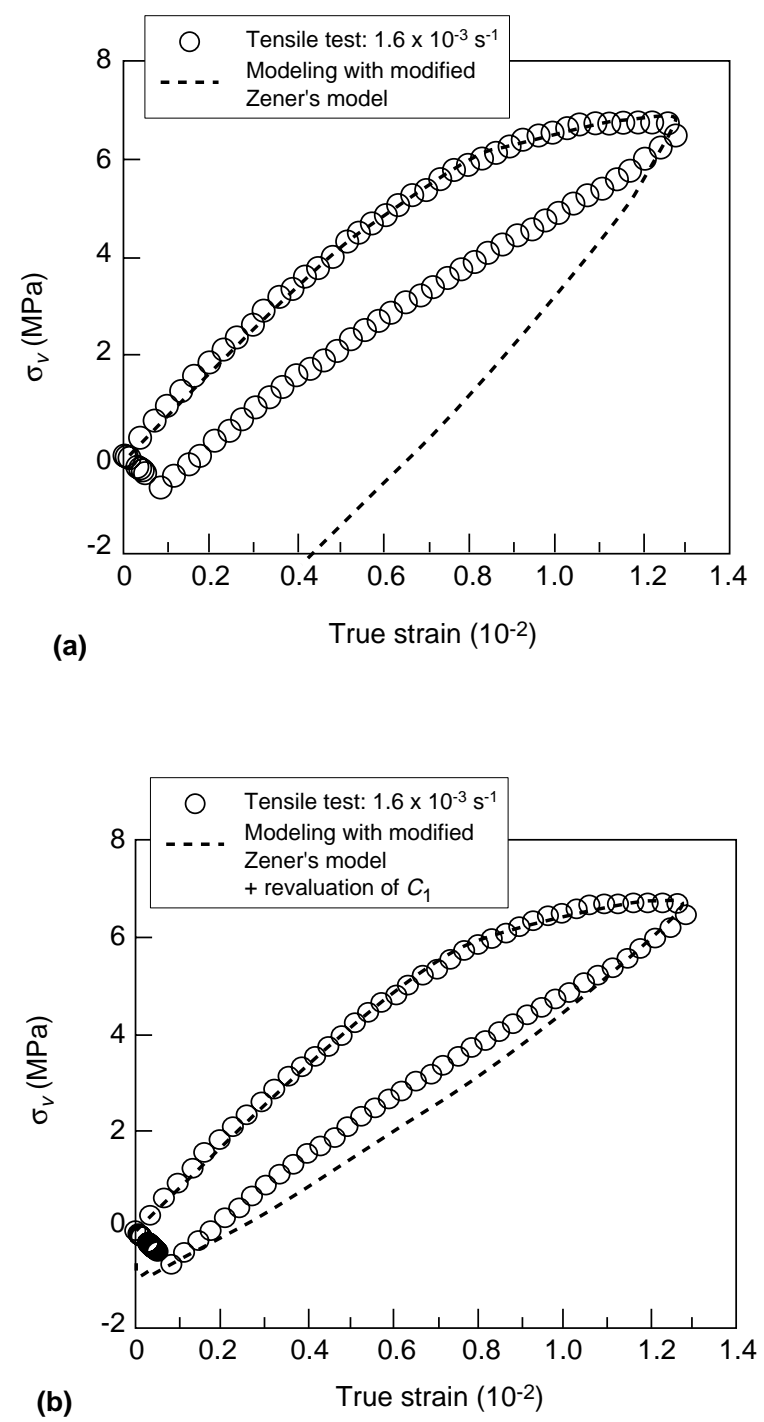

Figure 10

Viscous stress $v s$ true strain for a loading-unloading test performed up to $\varepsilon_{t}=1.3 \times 10^{-2}$ with $\dot{\varepsilon}=1.6 \times 10^{-3} \mathrm{~s}^{-1}$.

(a): superimposition of the response of the modified Zener's model. (b): superimposition of the response of the modified Zener's model where $C_{1}$ was revaluated at the strain reversal.

Zener's model is therefore able to model the viscoelastic behavior of the material providing that a function can describe the material viscosity whatever the macroscopic strain rate and the reached strain level: such a function was established as illustrated by Equation (7). In the studied strain rate range, the material viscosity $\eta$ can be formulated as:

$\eta=\frac{h_{0}-h_{1} \exp \left\{h_{2} \frac{\left|\dot{\varepsilon}_{1}\right|+3 \times 10^{-5}}{\left|\dot{\varepsilon}_{3}\right|}\right\}-h_{3} \exp \left\{h_{4} \frac{\left|\dot{\varepsilon}_{1}\right|+3 \times 10^{-5}}{\left|\dot{\varepsilon}_{3}\right|}\right\}}{\left(\left|\dot{\varepsilon}_{1}\right|+3 \times 10^{-5}\right)^{n e}}$ 
It's important to note that all the parameters of this dual exponential function are determined by interpolation of $\eta \times\left|\dot{\varepsilon}_{1}\right|{ }^{\text {ne }} v s\left|\dot{\varepsilon}_{1}\right| /\left|\dot{\varepsilon}_{3}\right|$ with Igor Pro application program so that the exponent ne permits the curves for the two extreme strain rates to be superposed.

As shown in Figure 10a, the modified Zener's Model with an elaborated $\eta$ expression reproduces stress-strain curves well for the constant loading rate condition. However, this model is not suitable for unloading path because the predicted unloading is more rapid than the experimental curve.

\subsection{Modeling under Unloading Condition}

According to Popelar et al. [4], one of the most severe tests of an anelastic material model is its ability to predict unloading. It is to be presumed that modeling the unloading of SCPs is rather difficult because of the weak number of works which deal with this subject. Popelar et al. [4] seem to belong to the few authors who are concerned with the unloading modeling: their analysis generally overpredicts the stress during the early stages of loading, then, during unloading, the predicted stresses are less than the measured values and the beginning of unloading is too stiff. Moreover, the $\sigma(\varepsilon)$ function they employed is different according to the sign of $\dot{\varepsilon}$.

It would therefore seem that the deformation mechanisms depend on the direction of loading path; which leads us to consider that the loading path acts on the stiffness $C_{1}$ of the amorphous phase. The origin of the $C_{1}$ decreasing evolution is rather physic. Let us consider a few macromolecules in a disturbed state in amorphous phase; it's easy to understand that the stretch of these chains results in a stiffness decrease of the whole. Consequently, these physical considerations would involve the evolution of the amorphous phase stiffness $C_{1}$ throughout the test.

In this paper, the revaluation of $C_{1}\left(C_{1 u}\right)$ is achieved at the loading path reversal considering the elastic nature of an equivalent material's total deformation. The amorphous phase stiffness after the reversal therefore depends both on the strain level $\varepsilon_{t}$ and the viscous stress stored during the forward loading:

$$
C_{1 u}=\frac{\sigma_{v}\left(\varepsilon_{t}\right)}{\varepsilon_{t}}
$$

Figure $10 \mathrm{~b}$ better shows the prediction of unloading test from the revaluation of the amorphous phase stiffness.

As shown in Figure 11, the viscoelastic model permits to correctly predict the mechanical response of PP under loading-unloading-recovery tests for different strain levels and strain rates.

\section{MODELING OF THE MECHANICAL BEHAVIOR OF THE SEMICRYSTALLINE POLYPROPYLENE IN STAGE II}

In Stage II, PP's behavior modeling is based on the stresses analysis performed from Cottrell's method (see Section 4). Macroscopic stress is divided into thermal and athermal

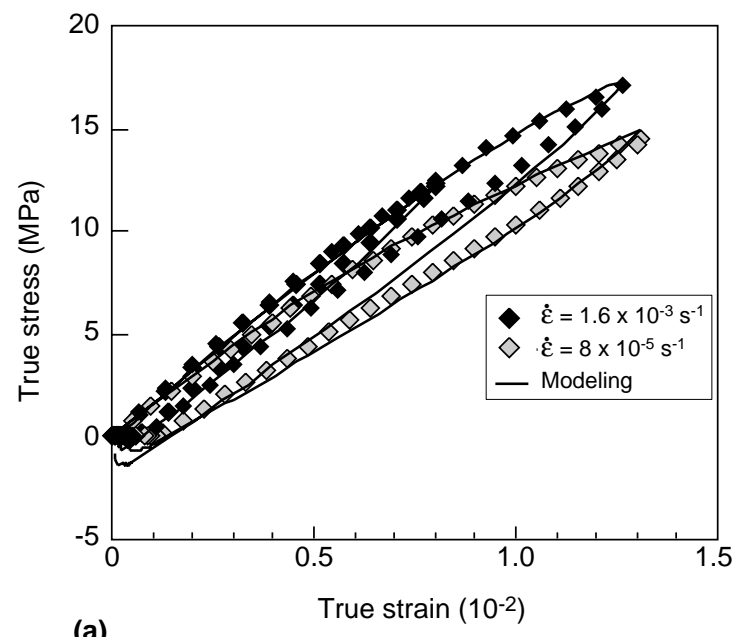

(a)

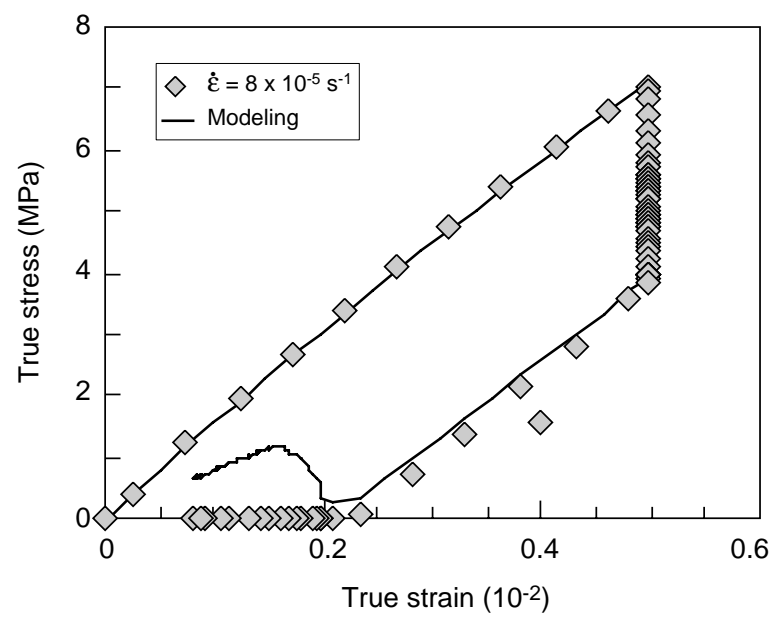

(b)

Figure 11

Viscoelastic model predictions.

(a): loading-unloading-recovery tests: $\dot{\varepsilon}=8 \times 10^{-5} \mathrm{~s}^{-1}\left(\varepsilon_{t}=1.3 \times 10^{-2}\right)$ and $\dot{\varepsilon}=1.6 \times 10^{-3} \mathrm{~s}^{-1}\left(\varepsilon_{t}=0.8 \times 10^{-2}-1.3 \times 10^{-2}\right)$. Superposing of the corresponding response of the viscoelastic model.

(b): loading-relaxation-unloading-recovery tests: strain rates of the loading and unloading paths $\dot{\varepsilon}=8 \times 10^{-5} \mathrm{~s}^{-1}\left(\varepsilon_{t}=0.5 \times 0^{-2}\right)$. Superposing of the corresponding response of the viscoelastic model. 
components of back stress and effective stress (Fig. 7b). The thermal component of effective stress is not represented on Figure $7 \mathrm{~b}$ because its quantity is negligible by comparison with the others.

\subsection{Evolutions of the Athermal Components of Back Stress and Effective Stress vs $\varepsilon_{v p}$}

The athermal back stress and athermal effective stress are respectively expressed as kinetic and isotropic hardening laws dependent on their corresponding viscoplastic strain:

$$
\begin{gathered}
\mathrm{d} X^{\mathrm{ath}}=C_{x} \mathrm{~d} \varepsilon_{v p}+\gamma_{x}\left(h_{p}-X^{\mathrm{ath}}\right)\left|\mathrm{d} \varepsilon_{v p}\right| \\
\mathrm{d} \sigma_{\mathrm{eff}}^{\mathrm{ath}}=b\left(\sigma_{1}-q-\sigma_{\mathrm{eff}}^{\mathrm{ath}}\right)\left|\mathrm{d} \varepsilon_{v p}\right|
\end{gathered}
$$

This one was deduced from the stabilized relaxed stress $\sigma_{2}: \varepsilon_{v p}=\varepsilon_{t}-\sigma_{2} / C_{2}$. Parameters $C_{x}, \gamma_{x}, h_{p}, b, \sigma_{1}$ and $q$ of these laws were determined from the experimental $X^{\text {ath }} v s \varepsilon_{v p}$ and $\sigma_{\text {eff }}^{\text {ath }} v s \varepsilon_{v p}$ evolutions (Fig. 12a).

Figure 12a shows that the viscoelastic limit $\Sigma_{0}$ is the sum of $h_{p}\left(\right.$ from $\left.X^{\text {ath }}\right)$ and $\sigma_{1}$ (from $\left.\sigma_{\text {eff }}^{\text {ath }}\right)$. Values of $h_{p}$ and $\sigma_{1}$ were obtained from a numerical way; the limit of viscoelasticity should also be investigated in compression to conclude on the decentring of the initial viscoelastic domain.

\subsection{Evolution of the Thermal Component of Effective Stress vs $\varepsilon_{v p}$}

The evolution of the viscous part of effective stress $\sigma_{\text {eff }}^{\text {th }} v s \varepsilon_{v p}$ is described from a type Norton's law. In this simple version of viscoplastic law, the equipotential surfaces of stresses space are any puissance functions of the viscous part of the stress [16]. In this paper, the viscoplastic strain rate $\left(\varepsilon_{v p}\right)$ is expressed from as follows:

$$
\dot{\varepsilon}_{v p}=\left(\frac{\left|\sigma-\left(X^{\text {ath }}+X^{\text {th }}\right)\right|-\sigma_{\text {eff }}^{\text {ath }}}{K}\right)^{n^{\prime}} \operatorname{sign}\left(\sigma-\left(X^{\text {ath }}+X^{\text {th }}\right)\right)
$$

or:

$$
\sigma_{\text {eff }}^{t h}=K\left(\dot{\varepsilon}_{v p}\right)^{1 / n^{\prime}}
$$

The two parameters $K$ and $n$ ' were not deduced from the experimental data; they were evaluated with the SiDoLo application program [17], whose main functions are to identify and optimize parameters of models.

\subsection{Evolution of the Thermal Component of Back Stress vs $\varepsilon_{v p}$}

As for the $X^{\text {th }} v s \varepsilon_{v p}$ evolution, the viscous nature of this thermal back stress led to also use Maxwell's model as $\sigma_{v} v s \varepsilon_{v l}$ :

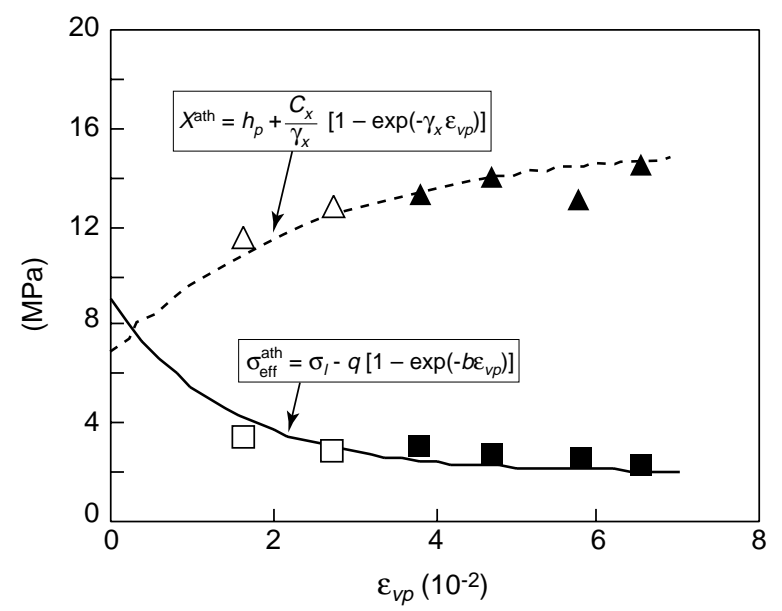

(a)

\begin{tabular}{|l}
$\Delta X^{\text {ath }}$ from relaxation tests \\
$\triangle X^{\text {ath }}=\sigma_{2}-\sigma_{\text {eff }}\left(\dot{\varepsilon}=1.6 \times 10^{-3} \mathrm{~s}^{-1}\right)$ \\
$\square \sigma_{\text {eff }}^{\text {ath }}$ from relaxation tests \\
$\square \sigma_{\text {eff }}\left(\dot{\varepsilon}=1.6 \times 10^{-3} \mathrm{~s}^{-1}\right)$
\end{tabular}

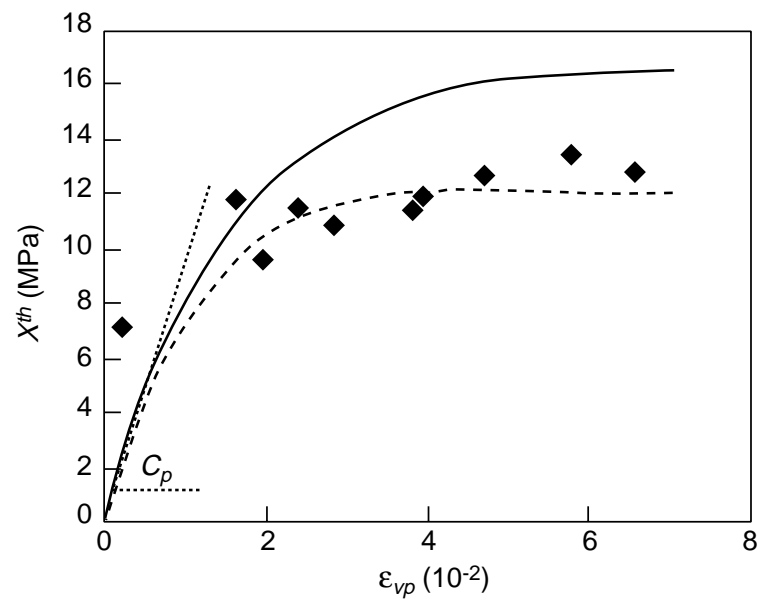

(b)

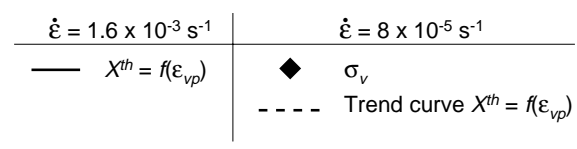

Figure 12

Determination of the parameters of the viscoplastic unit. (a): determination of the parameters of the kinetic and isotropic hardening laws. (b): $X^{\text {th }} v s \varepsilon_{v p}$ evolutions for $\dot{\varepsilon}=8 \times 10^{-5} \mathrm{~s}^{-1}$ and $1.6 \times 10^{-3} \mathrm{~s}^{-1}$. 


$$
\frac{\mathrm{d} X^{t h}}{\mathrm{~d} t}=C_{p}\left(\frac{\mathrm{d} \varepsilon_{v p}}{\mathrm{~d} t}-\frac{X^{t h}}{\eta_{p}}\right)
$$

By analogy with the viscoelastic unit (Section 5.3), the $C_{p}$ parameter is revaluated when the viscoplastic strain rate $\dot{\varepsilon}_{v p}$ becomes negative ( $t_{p u}$ instant), that is to say at the beginning of the reversal viscoplastic domain. The revaluated $C_{p}\left(C_{p u}\right)$ is obtained considering the elastic nature of an equivalent material's total viscoplastic strain:

$$
C_{p u}=\frac{X^{t h}\left(t_{p u}\right)}{\varepsilon_{v p}\left(t_{p u}\right)}
$$

\subsection{Viscosity Coefficient $\eta_{p}$ of the Viscoplastic Unit}

Viscosity coefficient $\eta_{p}$ of the viscoplastic unit is expressed as $\eta(E q .(7))$ :

$$
\eta_{p}=\frac{h_{5}-h_{6} \exp \left\{h_{7} \frac{\left|\dot{\varepsilon}_{4}\right|+10^{-6}}{\left|\dot{\varepsilon}_{5}\right|}\right\}-h_{8} \exp \left\{h_{9} \frac{\left|\dot{\varepsilon}_{4}\right|+10^{-6}}{\left|\dot{\varepsilon}_{5}\right|}\right\}}{\left(\left|\dot{\varepsilon}_{4}\right|+10^{-6}\right)^{n p}}
$$

The different parameters of $\eta_{p}$ are determined from the experimental $X^{\text {th }}$ vs $\varepsilon_{v p}$ evolutions obtained for $\dot{\varepsilon}=1.6 \times 10^{-3} \mathrm{~s}^{-1}$ and $\dot{\varepsilon}=8 \times 10^{-5} \mathrm{~s}^{-1}$. At $\dot{\varepsilon}=1.6 \times 10^{-3} \mathrm{~s}^{-1}, X^{\text {th }}$ was directly deduced from the difference between the apparent back stress $X$ and the athermal part of back stress $X^{\text {ath }}$ because the apparent effective stress values are close to the athermal effective stress values at this strain rate [7]. However, for the lowest

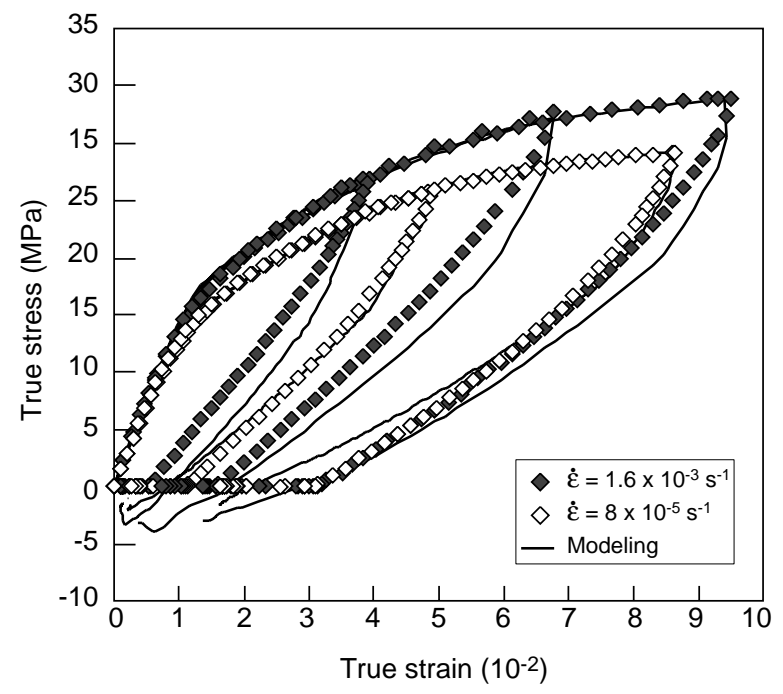

Figure 13

Viscoelastoplastic model predictions. Loading-unloadingrecovery tests: $\dot{\varepsilon}=8 \times 10^{-5} \mathrm{~s}^{-1}\left(\varepsilon_{t}=4.9 \times 10^{-2}-8.6 \times 10^{-2}\right)$ and $\dot{\varepsilon}=1.6 \times 10^{-3} \mathrm{~s}^{-1}\left(\varepsilon_{t}=3.9 \times 10^{-2}-6.8 \times 10^{-2}-9.5 \times 10^{-2}\right)$. Superposing of the corresponding response of the viscoelastoplastic model. strain rate $\left(8 \times 10^{-5} \mathrm{~s}^{-1}\right)$, it is not possible to distinguish the thermal components of effective and back stresses: $X^{\text {th }}$ was therefore approximated by $\sigma_{v}$. As for the viscoplastic strain values corresponding to $X^{\text {th }}$ values, they were evaluated from the viscoelastic model as follows: $\varepsilon_{v p}=\varepsilon_{t}-\varepsilon_{v l}^{\text {model }}$, where $\varepsilon_{v l}^{\text {model }}$ is the strain response of the viscoelastic modeling.

The initial common slope of $X^{\text {th }} v s \varepsilon_{v p}$ evolutions allows the determination of the $C_{p}$ parameter (Fig. 12b). The different parameters of $\eta_{p}$ in the studied strain rate range were obtained by interpolation of $\eta_{p} \times\left|\dot{\varepsilon}_{4}\right|^{n p} v s\left|\dot{\varepsilon}_{4}\right| /\left|\dot{\varepsilon}_{5}\right|$ so that the exponent $n p$ permits the curves for the two extreme strain rates to be superposed.
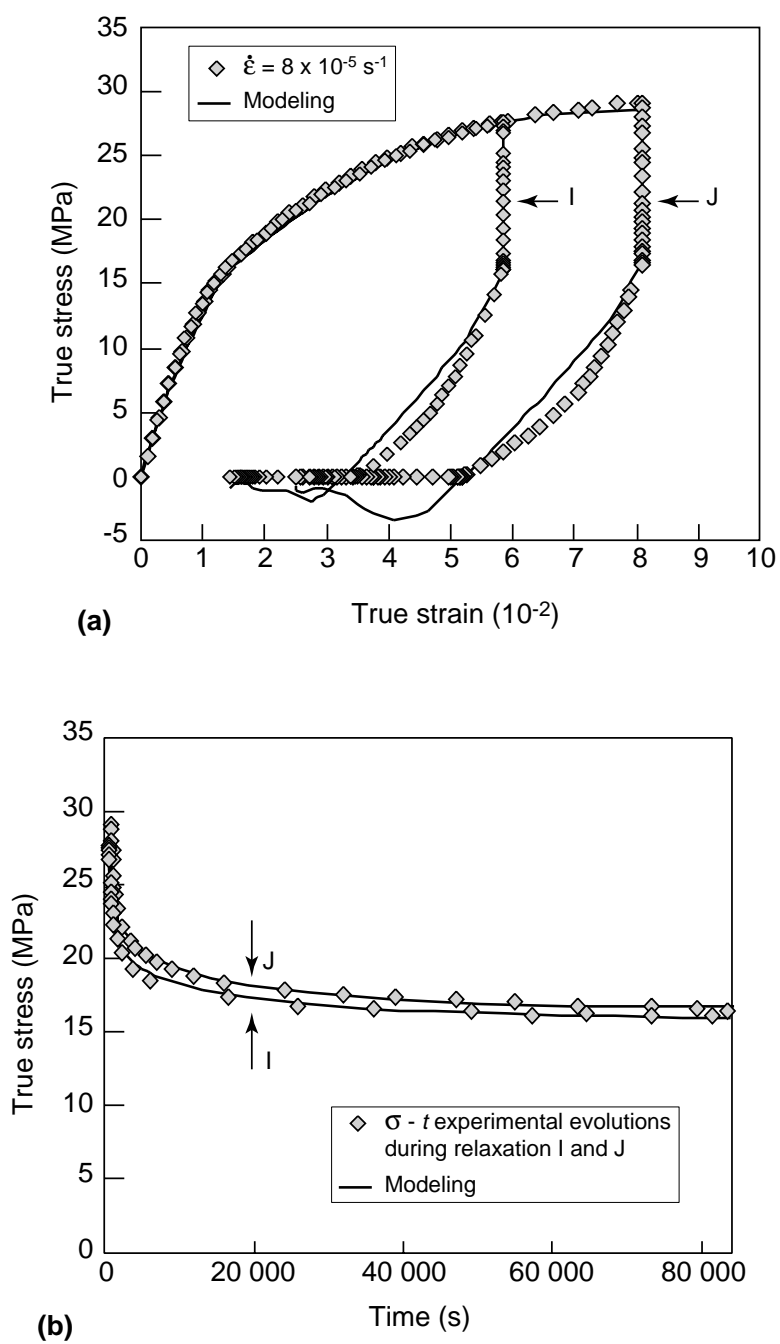

Figure 14

Viscoelastoplastic model predictions. Loading-relaxationunloading-recovery tests: strain rates of the loading and unloading paths $\dot{\varepsilon}=8 \times 10^{-5} \mathrm{~s}^{-1}\left(\varepsilon_{t}=5.8 \times 10^{-2}-8.1 \times 10^{-2}\right)$.

(a): $\sigma-\varepsilon$ experimental evolutions. Superposing of the corresponding response of the viscoelastoplastic model.

(b): $\sigma-t$ experimental evolutions. Superposing of the corresponding response of the viscoelastoplastic model. 
It can be noticed with the experimental loading-unloading curves that loading curves are much more affected by viscosity than unloading curves: which means that the viscosity coefficient is more important during unloading. A difference of the slipping way between loading and unloading path may explain this feature. The viscosity coefficient $\eta_{p}$ must therefore be modified for unloading path. In order not to introduce an additional function, the exponential term responsible for the quick decrease of $\eta_{p}$ was arbitrarily removed from the $\eta_{p}$ function for unloading test.

It is not necessary to perform this change on the $\eta$ function of the viscoelastic unit because the evolution of viscosity in viscoelastic domain is always weaker than the evolution of viscosity in the viscoplastic domain (in particular when the strain level reached at the end of forward loading is important).

In Figure 13 and Figure 14, the superimposition of the response of the viscoelastoplastic model on experimental results of loading-unlaoding-recovery tests and loadingrelaxation-unloading-recovery tests shows that the elaborated model is able to predict this sort of tests for different strain levels. As for the prediction of unloading path, improvements could be brought to the mathematic model to take the discontinuity of deformation at the strain reversal into account: this discontinuity is all the more important since the strain rate is high. The parameters employed for PP are presented in Table 1.

TABLE 1

Values of the parameters employed in the viscoelastoplastic model

\begin{tabular}{|c|c|}
\hline Parameters & Values \\
\hline$C_{1}$ & 830 \\
\hline$C_{2}$ & 790 \\
\hline$h_{0}$ & 52.60 \\
\hline$h_{1}$ & 28.10 \\
\hline$h_{2}$ & -0.52 \\
\hline$h_{3}$ & 21.30 \\
\hline$h_{4}$ & -0.48 \\
\hline ne & 0.82 \\
\hline$h_{5}$ & 23.35 \\
\hline$h_{6}$ & 16.91 \\
\hline$h_{7}$ & -0.51 \\
\hline$h_{8}$ & 6.38 \\
\hline$h_{9}$ & -2.61 \\
\hline$n p$ & 0.94 \\
\hline$C_{p}$ & 1050 \\
\hline$C_{x}$ & 335 \\
\hline$\gamma_{x}$ & 40 \\
\hline$h_{p}$ & 6.9 \\
\hline$b$ & 70 \\
\hline$\sigma_{l}$ & 9 \\
\hline$q$ & 7 \\
\hline$K$ & 50 \\
\hline$n^{\prime}$ & 2.10 \\
\hline
\end{tabular}

\section{CONCLUSION}

Some uniaxial mechanical tests have permitted to reveal the presence of a viscoelastic domain, then of a viscoplastic domain in the pre-necking domain of PP. Plasticity was thus evidenced before necking. The viscoplastic domain was more precisely characterized from approaches developed in metals. The influence of time on the mechanical behavior of the SCP was also studied to take the viscosity of the material into account.

An uniaxial model based on the characterization of the viscoelastoplastic behavior of PP was developed to predict a few loading paths before necking. The emphasis was particularly placed on the unloading prediction. The proposed model permits to correctly predict loading-unloading tests and loading-relaxation-unloading tests for different strain levels in a range of strain rates.

In the short term, the revaluation of the amorphous phase stiffness $C_{1}$ is planned to be generalized throughout the loading path, and no longer in a selective way. Moreover, the model has to be tested under other kinds of paths: for example, under tests with some leaps of strain rate, under tests with several loops of loading paths as loadingunloading paths or loading-unloading-recovery paths. In the longer term, the uniaxial model will be extended in 2D from a study of the SCP behavior under multiaxial mechanical tests in order to insert it in a computer code; the aim being to predict the behavior of composite structures composed of a PP matrix.

\section{ACKNOWLEDGEMENTS}

The authors are grateful for the contribution of the technical staff and for the financial support of Région Picardie.

\section{REFERENCES}

1 Pardos, F. (1999) Forecast for the World Plastics Industry to 2020. Plastics Engineering, 55, 11, 53-57.

2 Dupend-Brusselle, N. (2000) Comportement viscoélastoplastique d'un polymère semi-cristallin, le polypropylène, avant la striction : caractérisation expérimentale et modélisation phénoménologique. Thèse, université de technologie de Compiègne.

3 Olley, R.H. and Bassett, D.C. (1982) An Improved Permanganic Etchant for Polyolefines. Polymer, 23, 11, 1707-1710.

4 Popelar, C.F., Popelar, C.H. and Kenner, V.H. (1990) Viscoelastic Material Characterization and Modeling for Polyethylene. Polymer Engineering and Science, 30, 10, 577586.

5 Zhang, C. and Moore, I.D. (1997) Nonlinear Mechanical Response of High Density Polyethylene. Part I: Experimental Investigation and Model Evaluation. Part II: Uniaxial Constitutive Modeling. Polymer Engineering and Science, 37, 2, 404-420. 
6 Kitagawa, M. and Matsutani, T. (1988) Effect of Time and Temperature on Nonlinear Constitutive Equation in Polypropylene. Journal of Materials Science, 23, 4085-4090.

7 Brusselle-Dupend, N., Lai, D., Feaugas, X., Guigon, M. and Clavel, M. (2001) Mechanical Behavior of a Semicrystalline Polymer before Necking. Part I: Characterization of Uniaxial Behavior. Polymer Engineering and Science, 41, 1, 66-76.

8 Zener, C. (1948) Elasticity and Anelasticity of Metals, Chicago University Press, Chicago.

9 Prager, W. and Hodge, P.G. (1951) Theory of Perfectly Plastics Solids, John Wiley and Sons, New York.

10 Cottrell, A.H. (1953) Dislocations and Plastic Flow in Polycristals, Oxford University Press, London.

11 Kuhlmann-Wilsdorf, D. and Laird, C. (1979) Dislocation Behavior in Fatigue. II. Friction Stress and Back Stress as Inferred from an Analysis of Hysteresis Loops. Material Science and Engineering, 37, 2, 111-120.

12 Dickson, J.I., Boutin, J. and Handfield, L. (1984) A Comparison of Two Simple Methods for Measuring Cyclic Internal and Effective Stresses. Material Science and Engineering, 64, 1, L7-11.
13 Feaugas, X. (1994) Microstructure et modélisation du comportement en fatigue uniaxiale et multiaxiale d'un alliage de titane biphasé. Thèse, université de technologie de Compiègne.

14 Feaugas, X. (1999) Contribution à la compréhension des mécanismes de déformation plastique et d'endommagement des matériaux : un point de vue expérimental. Habilitation à diriger des recherches, université de technologie de Compiègne.

15 Feaugas, X. (1999) On the Origin of the Tensile Flow Stress in the Stainless AISI 316L at $300 \mathrm{~K}$ : Back Stress and Effective Stress. Acta Materiala, 47, 13, 3617-3632.

16 Chaboche, J.L. (1995) Formalisme général des lois de comportement : application aux métaux et polymères, in Introduction à la mécanique des polymères, G'Sell, C. and Haudin, J.M.(éd.), Institut national polytechnique de Lorraine.

17 Pilvin, P. (1999) Manuel d'utilisation du logiciel SiDoLo (Simulation et iDentification de Lois de comportement), École centrale de Paris.

Final manuscript received in January 2002 